\title{
The effect of Vancomycin degradation products in the topical treatment of osteomyelitis
}

\author{
Melichercik $\mathrm{P}^{1}$, Klapkova $\mathrm{E}^{2}$, Landor $\mathrm{I}^{1}$, Judl $\mathrm{T}^{1}$, Sibek $\mathrm{M}^{1}$, Jahoda $\mathrm{D}^{1}$ \\ Department of Orthopaedics, First Faculty of Medicine, Charles University in Prague and Motol \\ University Hospital, Prague, Czech Republic. pmeliche@seznam.cz
}

\begin{abstract}
Background: The topical application of Vancomycin is increasingly being used in orthopedics because of the development of methicillin resistant bacteria. Consequently, resistance to Vancomycin has recently been on the rise. One possible explanation for this phenomenon could be the thermal degradation of Vancomycin to antibacterially inactive crystalline degradation products (CDP-1s). The aim of our in vitro experiment was to compare the creation and elution characteristics of CDP-1s and the active form of Vancomycin (factor B) released from bone grafts. Methods: CDP-1s and the factor B released from bone grafts into the buffer solution were measured using the high-performance liquid chromatography method at progressive intervals.

Results: The factor B was released from bone grafts at the highest levels, typically on the first day (618.8 mg/L). CDP-1 levels kept increasing until the end of measurement on day 15, when the concentration of CDP-1s (1280.7 $\mathrm{mg} / \mathrm{L})$ was much higher compared to that of factor B $(217.5 \mathrm{mg} / \mathrm{L})$.

Conclusions: We confirmed the tendency of Vancomycin to convert to antimicrobially ineffective CDP-1s. Although Vancomycin is decomposed into crystalline degradation products, its active forms are released from bone grafts in sufficient concentration for more than two keks (Tab. 3, Fig. 1, Ref. 15). Text in PDF www.elis.sk. Key words: osteomyelitis, resistant bacterial infection, local antibiotic carriers, crystalline degradation products of Vancomycin.
\end{abstract}

The treatment of osteomyelitis must be comprehensive and long term. One of the ways to increase therapeutic potential is to use local antibiotic delivery system $(3,8,10,13,14,15)$. The topical antibiotic treatment of musculoskeletal infections has the advantage over systemic antibiotics of achieving high antibiotic concentrations, exceeding the minimum inhibitory concentration (MIC) without increasing systemic toxicity. Locally delivered antibiotics work even in the avascular zones and on the planktonic forms of bacteria and sessile bacteria known as biofilm. Local carriers of antibiotics also fill the space created after the removal of the necrotic bone tissue $(7,8)$.

Local carriers of antibiotics used in orthopaedics can be divided according to composition into synthetic and natural polymers,

\footnotetext{
${ }^{1}$ Department of Orthopaedics, First Faculty of Medicine, Charles University in Prague and Motol University Hospital, Prague, Czech Republic, and ${ }^{2}$ Department of Medical Chemistry and Biochemistry, Second Faculty of Medicine, Charles University in Prague and Motol University Hospital, Prague, Czech Republic
}

Address for correspondence: P. Melichercik, MD, Department of Orthopaedics, First Faculty of Medicine, Charles University in Prague and Motol University Hospital, V Uvalu 84, CZ-150 06 Prague 5, Czech Republic. Phone: +420.732 .167822$

Acknowledgement: This work was supported by institutional grant No. 00064203 from the Ministry of Health of the Czech Republic for the conceptual development of research organizations (Motol University Hospital, Prague, Czech Republic), Internal Grant of the Motol University Hospital, Prague, Czech Republic, “Modern Therapy” for the project „Local treatment of osteomyelitis with antimicrobial peptides released from local carriers used in orthopaedics", No. 9777 and grant No. NT/14218 from the Internal Grant Agency of Ministry of Health of the Czech Republic. ceramics, composites, and bone grafts. The most often utilized materials are polymethyl methacrylate (PMMA), bone grafts, calcium sulphate and carbonate, and collagen $(8,9,10)$.

The antibiotics appropriate for local administration thanks to their stability include: glycopeptides, aminoglycosides, macrolides, and lincosamides (11).

Since the 1950s, Vancomycin has been used to treat severe infections caused by Gram-positive microorganisms. Demand peaked worldwide at the end of the twentieth century as a result of the rise in methicillin/oxacillin resistant Staphyloccocus aureus (MRSA) and Staphyloccocus epidermidis (MRSE) strains (12). With the increasing incidence of MRSA in chronically and seriously ill patients, Vancomycin became more widely used. This led in turn to the emergence of MRSA strains resistant to glycopeptides (multiple MRSA phenotype). Vancomycin resistant Staphylococcus aureus (VRSA) is most common in elderly patients with leg ulcers or pressure sores, especially in those with a history of Vancomycin-resistant enterococci. These enterococci as potential carriers of the vanA gene responsible for resistance to Vancomycin can transfer the gene to Staphyloccocus aureus $(1,2,5)$.

One possible explanation for why infections caused by VRSA are more often noted might be that Vancomycin breaks down over time to form crystalline degradation products (CDP-1s). At the same time, the active form of Vancomycin (factor B) decreases. There are two CDP-1 isomers: CDP-1M (major) and CDP-1m (minor). Both degradation products are devoid of antibacterial activity due to the disruption of the hydrogen bond at the antigen binding site of a specific Vancomycin receptor (12). 
The aim of this in vitro experiment was to monitor the concentrations of active forms of Vancomycin and its degradation products released from the bone grafts used as local antibiotic carriers in the treatment of osteomyelitis.

\section{Material and methods}

For the in vitro experiment, morselized cancellous bone grafts were chosen as local antibiotic carriers due to their appropriate properties and availability $(1,3,5,8,9,10)$. For antibiotic impregnation of bone grafts, Vancomycin powder (Vancomycin Mylan ${ }^{\circledR}$ ) was used. Sample preparation was done under sterile conditions.

Bone grafts were harvested from femur heads from hip replacement patients who had provided written consent. Bone grafts free of fibrous tissue, cartilage and cortical layers were prepared during surgery in the operating room. Cancellous bone was minced with a standard bone grinder (ProSpon, grater hole diameter of $4.5 \mathrm{~mm}$ ).

Morselized bone grafts weighing $70 \mathrm{~g}$ were impregnated with Vancomycin powder at a rate of $2.5 \mathrm{~g}$ per $100 \mathrm{~g}$ bone graft over 35 minutes. The ratio of bone graft and antibiotics was derived from the amount of Vancomycin in commercially available bone cement.

Sixty-six $1 \mathrm{~g}$ samples were obtained from Vancomycin impregnated bone grafts. Each sample was put on a sterile gauze pad and was firmly caulked, put into a separate $50 \mathrm{ml}$ tube with $20 \mathrm{ml}$ of phosphate buffer ( $\mathrm{pH} 7.4$ ), and placed in a thermostat at $37^{\circ} \mathrm{C}$.

After gentle manual mixing, the six tubes containing the samples were sampled under sterile conditions at progressive intervals for 15 days; the concentrations of the released active form of Vancomycin and its degradation products were measured in the buffer. These tubes were not used for further measurements.

Vancomycin and its crystalline degradation products were determined by HPLC on an Agilent 1200 series system equipped with a diode array detector (DAD) (Agilent Technologies, USA). Cefazolin was used as an internal standard. A $200 \mu 1$ sample was collected and added to $200 \mu \mathrm{l}$ of water and $200 \mu$ l of the internal standard. Samples were purified by solid phase extraction (SPE) on Waters Sep-Pak ${ }^{\circledR}$ Vac C18 cartridges 3cc/500 mg 55-10. Extraction columns were conditioned by washing with methanol and water. The samples were aspirated into the columns and then washed with water. The samples were eluted with $800 \mu 1$ of $0.05 \mathrm{M}$ $\mathrm{KH}_{2} \mathrm{PO}_{4}$ : acetonitrile (3:7) and then with $800 \mu \mathrm{l}$ of acetonitrile: water $(1: 1)$. The eluate was dried under an air stream at $50{ }^{\circ} \mathrm{C}$ for 10 minutes. The prepared sample was injected onto the column. The analysis was carried out at $210 \mathrm{~nm}$ and a mobile phase flow rate of $1.5 \mathrm{ml} / \mathrm{min}$. A mobile phase gradient was used. The mobile phase consisted of two components: A: $0.05 \mathrm{M}$ phosphate buffer (pH 6): acetonitrile: methanol (91:5:4) and B: $0.05 \mathrm{M}$ phosphate buffer: acetonitrile: methanol (84:8:8). The gradient conditions were as follows: $100 \%$ A for $2 \mathrm{~min}$, increase to $100 \%$ B over $9 \mathrm{~min}$, left for 14 minutes, increase to $100 \%$ A over 5 minutes, and left for 5 minutes. The analysis was carried out on a Zorbax SB-AQ column, $4.6 \times 250 \mathrm{~mm}, 5$ micron (Agilent Technologies). The analysis time was 30 minutes. Vancomycin, cefazolin, methanol, and acetonitrile were supplied by Sigma-Aldrich. Crystalline degradation products of Vancomycin were from RatioChem Ltd (Czech Republic).

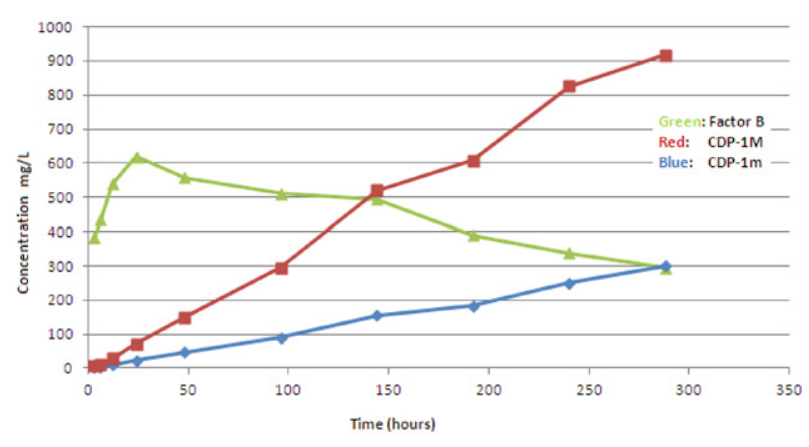

Fig. 1. Concentrations of vancomycin and its crystalline degradation products.

\section{Results}

In the first measurement, three hours after the application of the samples, the average concentrations were $381.63 \mathrm{mg} / \mathrm{L}$ for released factor B, $3.2 \mathrm{mg} / \mathrm{L}$ for CDP- $1 \mathrm{~m}$, and $5.7 \mathrm{mg} / \mathrm{L}$ for CDP-1M.

The highest average concentration of factor $\mathrm{B}(618.8 \mathrm{mg} / \mathrm{L})$ was achieved on the first day while the levels of both CDP-1 subtypes were less than $95 \mathrm{mg} / \mathrm{L}$.

On the fourth day, the average concentration of CDP-1 (384 $\mathrm{mg} / \mathrm{L})$ was similar to that of factor B $(510.5 \mathrm{mg} / \mathrm{L})$.

On the following days, the concentration of factor B started to fall and the CDP-1 levels increased until the end of the measurement period on day 15. CDP-1M achieved the highest concentration $(959.8 \mathrm{mg} / \mathrm{L})$. The average concentration of CDP- $1 \mathrm{~m}$ was $320.9 \mathrm{mg} / \mathrm{L}$ and that of factor B was $217.5 \mathrm{mg} / \mathrm{L}$.

The average concentrations of factor B, CDP-1M, and CDP- $1 \mathrm{~m}$ released from bone grafts into the surrounding buffer solution are shown in Figure 1. The average concentrations of factor B, CDP-1M, and CDP-1 $\mathrm{m}$ in $\mathrm{mg} / \mathrm{L}$ (Mean), strength of T - test (T), and significance ( $\mathrm{p}$ value) at different time intervals are given in Tables 1, 2, and 3.

Tab. 1. Factor B (active form of vancomycin) levels.

\begin{tabular}{rcccc}
\hline Time $(\mathrm{h})$ & No of samples & Mean level & Range & $\mathrm{p}$ value \\
\hline 3 & 6 & 381.63 & $336.5-440.8$ & \\
6 & 6 & 435.53 & $372.9-506.16$ & 0.0575 \\
12 & 6 & 538.25 & $429-641$ & 0.0285 \\
24 & 6 & 618.88 & $580.9-656.5$ & 0.0746 \\
48 & 6 & 558.42 & $526.1-602$ & 0.0044 \\
96 & 6 & 510.5 & $450.2-569.3$ & 0.0100 \\
144 & 6 & 493.3 & $464.9-572.1$ & 0.5522 \\
192 & 6 & 389.18 & $352.3-518.1$ & 0.0152 \\
240 & 6 & 337.9 & $303.1-420.3$ & 0.1320 \\
288 & 6 & 295.8 & $259.8-375.1$ & 0.1322 \\
336 & 6 & 217.5 & $208.5-230.7$ & 0,0073 \\
\hline
\end{tabular}


Tab. 2. CDP-1M (Crystalline Degradation Product - Major) levels.

\begin{tabular}{ccccc}
\hline Time $(\mathrm{h})$ & No of samples & Mean level & Range & $\mathrm{p}$ value \\
\hline 3 & 6 & 5.7 & $2-7.5$ & 0.0005 \\
6 & 6 & 12.4 & $8.8-15.3$ & 0.0001 \\
12 & 6 & 29.3 & $22.5-36.9$ & 0.0001 \\
24 & 6 & 72.2 & $61.7-81.4$ & 0.0001 \\
48 & 6 & 150.2 & $137.4-171.6$ & 0.0001 \\
96 & 6 & 294.5 & $259.2-339.4$ & 0.0022 \\
144 & 6 & 519.5 & $490.1-597.6$ & 0.0411 \\
192 & 6 & 607.2 & $552.4-786.6$ & 0.0043 \\
240 & 6 & 825.8 & $739.8-900.1$ & 0.0226 \\
288 & 6 & 917.8 & $815.4-998.7$ & 0.2223 \\
336 & 6 & 959.8 & $914-1053.1$ & \\
\hline
\end{tabular}

Tab. 3. CDP-1m (Crystalline Degradation Product - Minor) levels.

\begin{tabular}{ccccc}
\hline Time $(\mathrm{h})$ & No of samples & Mean level & Range & $\mathrm{p}$ value \\
\hline 3 & 6 & 3.2 & $1.8-3.9$ & 0.0027 \\
6 & 6 & 5.0 & $4.0-6.1$ & 0.0001 \\
12 & 6 & 9.9 & $7.9-11.9$ & 0.0001 \\
24 & 6 & 22.4 & $19.9-25.8$ & 0.0001 \\
48 & 6 & 46.6 & $43.1-52.6$ & 0.0001 \\
96 & 6 & 89.5 & $77.5-102.8$ & 0.0022 \\
144 & 6 & 155.3 & $146.2-177.8$ & 0.0411 \\
192 & 6 & 182.5 & $167.3-234.9$ & 0.0043 \\
240 & 6 & 250.5 & $222.1-293.1$ & 0.0106 \\
288 & 6 & 299.8 & $270.2-352.1$ & 0.2729 \\
336 & 6 & 320.9 & $285.9-370.1$ & \\
\hline
\end{tabular}

\section{Discussion}

Vancomycin, a member of the group of glycopeptide antibiotics, is among the products that are currently used in the treatment of serious infections caused by methicillin-resistant Staphylococcus aureus (MRSA) and methicillin-resistant coagulase-negative Staphylococcus (MRCoNS). Vancomycin is a bactericidal antibiotic produced by a bacterium Amycolatopsis orientalis. Possible disadvantages occuring during systemic exposure may be relatively frequent side effects and the risk of nephrotoxicity, especially in situations where used in high doses to achieve a reliable inhibitory concentration at the infection site (6). Therefore, topical Vancomycin is an optimal option whenever possible. It is, inter alia, an epidemiologically safer alternative to the systemic Vancomycin that poses the risk of inducing resistance because of low, subinhibitory concentrations that may occur in some areas of the body, especially during long-term treatment (4).

Other disadvantages of Vancomycin are its selective activity against Gram-positive bacteria and its lack of effect on sessile biofilm bacteria. Therefore, it is preferable to use topical Vancomycin delivered from a carrier system in combination with other antibiotics, e.g. gentamycin or tobramycin $(7,9)$.

One possible explanation for the increase in VRSA could be the thermal degradation of Vancomycin (12). This finding appeared when the monitoring of Vancomycin levels in the serum was started, particularly in patients with reduced renal function, because of nephrotoxicity and ototoxicity observed after systemic administration of Vancomycin. It was found that the temperature of the human body leads to thermal degradation of Vancomycin with the formation of crystalline degradation products (CDP-1s) and a decrease in active forms of Vancomycin (factor B) (12). Increased production of CDP-1s was observed in patients with impaired renal function due to the prolonged half-life of antibiotics. Accumulation of CDP-1 can cause toxic damage to the tissues or may result in treatment failure due to underdosing with Vancomycin . Results from in vitro experiments and in vivo studies have confirmed that the degradation of Vancomycin to CDP-1s is dependent on temperature and heat duration. During in vitro at a temperature of $20-25^{\circ} \mathrm{C}$, up to $50 \%$ of Vancomycin is converted to CDP-1s within 16 hours, and $90 \%$ of Vancomycin is converted to CDP-1s within 40 hours. Also an acidic $\mathrm{pH}$ (4.1 to 4.2) contributes to the formation of CDP-1s. The elimination half-life of Vancomycin is 5-11 hours in healthy adult humans and 5 days or more in patients with impaired renal function. The pharmacokinetics of CDP-1s have not yet been evaluated. Their half-life and elimination pathways are still unknown (12).

In our in vitro experiment, Vancomycin was converted to degradation products at a much slower rate than reported by Somerville. The concentrations of factor B released into the surrounding buffer were almost comparable with those of degradation products released until the 4th day. Then there was a gradual decline in factor B and a steeper increase in CDP-1s. The slower degradation process of Vancomycin could well be caused by the high local concentrations of the antibiotic. In our experiment, there were not many factors that could have accelerated Vancomycin degradation as there are in a living organism. The exact cause of this effect is unknown. From the 4th day after placing the carriers into the tubes, gradually a disproportionate increase in CDP-1s was seen in the surrounding buffer. This might be due to the conversion of the released factor B into CDP-1s and the release of CDP-1s already formed in the bone grafts. Therefore, at the end of the experiment factor B was evident in a much lower concentration.

However, despite the considerable tendency of Vancomycin towards crystalline thermal degradation, the levels of the released active form of Vancomycin were above the MIC for VRSA for more than 2 weeks. These results suggest that the local application of high-dose Vancomycin via the use of drug delivery carriers is a safe therapeutic method in osteomyelitis treatment that prevents the development of bacterial resistance. The questions that arise 
are: what happens to CDP-1s in the human body and what effect do they have on the surrounding tissues; or whether they just cause bacterial resistance to Vancomycin or other glycopeptide antibiotics. Another problem could be the use of Vancomycin in bone cement (polymethyl methacrylate). Exothermic reaction of the bone cement during its polymerization can accelerate the conversion of Vancomycin into crystalline degradation products and thus cause a significant decrease in antimicrobial activity. This issue will be addressed in another study.

\section{References}

1. Appelbaum PC. Reduced glycopeptide susceptibility in methicillinresistant Staphylococcus aureus (MRSA). Int J Antimicrob Agents 2007; 30: $398-408$.

2. Bert F, Leflon-Guibout V, Le Grand J, Bourdon N, Nicolas.Chanoine MH. Emergence of vancomycin-dependent enterococci following glycopeptide therapy: case report and review. Pathol Biol (Paris) 2009; 57: 56-60.

3. Buttaro M, Gimenez MI, Greco G, Barcan L, Piccaluga F. High local levels of vancomycin without nephrotoxicity released from impacted bone allograft in 20 revision hip arthroplasties. Acta Orthopaed 2005; 76: 336-340.

4. Campoccia D, Montanaro L, Speziale P, Arciola CR. Antibioticloaded biomaterials and the risks for the spread of antibiotic resistance following their prophylactic and therapeutic clinical use. Biomaterials 2010; 31: 6363-7637.

5. Chang S, Sievert DM, Hageman JC, Boulton ML, Tenover FC, Downes F, Shah S, Rudrik JT, Pupp GR, Brown WJ, Cardo D, Fridkin SK. Infection with vancomycin-resistant Staphylococcus aureus containing the vanA resistance gene. N Engl J Med 2003; 348: 1342-1347.
6. Cunha BA. Vancomycin revisited: a reappraisal of clinical use. Crit Care Clin 2008; 24: 393-420.

7. Jahoda D, Sosna A, Nyč O et al. Infekční komplikace kloubních náhrad. Praha: Triton, 2008.

8. Jahoda D, Nyč O, Pokorný D, Landor I, Sosna A. Antibiotika v prevenci infekčních komplikací u operací kloubních náhrad. Acta Chir Orthop Traum Cech 2006; 73: 108.

9. Meani E, Romanò C, Crosby L, Hofmann G. Infection and Local Treatment in Orthopedic Surgery. US: Springer, 2007.

10. Melicherčík P, Jahoda D, Nyč O, Klapková E, Barták V, Landor I, Pokorný D, Krůta T, Sosna A. Bone grafts as a vancomycine carrier for local therapy of resistant infections. Folia Microbiol 2012.

11. Randelli P, Evola FR, Cabitza P, Polli L, Denti M, Vaienti L. Prophylactic use of antibiotic-loaded bone cement in primary total knee replacement. Knee Surg Sports Traumatol Arthrosc 2009; 18: 181-186.

12. Somerville AL, Wright DH, Rotschafer JC. Implications of Vancomycin Degradation Products on Therapeutic Drug Monitoring in Patiens with End-Stage Renal Disease. Pharmacotherapy 1999; 19: 702-707.

13. Winkler H, Janata $\mathbf{O}$, Berger $C$, Wein $\mathbf{W}$, Georgopoulos $A$. In vitro release of vancomycin and tobramycin from impregnated human and bovine bone grafts. J Antimicrob Chemother 2000; 46: 423-428.

14. Winkler H, Stobier A, Kaudela K, Winter F, Menschik F. One stage uncemented revision of infected total hip replacement using cancellous allograft bone impregnated with antibiotics. J Bone Joint Surg Br 2008; 90: $1580-1584$.

15. Witso E, Persen L, Loseth K, Benum P, Bergh K. Cancellous bone as an antibiotic carrier. Acta Orthop Scand 2000; 71: 80-84.

Received February 25, 2014. Accepted June 9, 2014. 